DOI: https://doi.org/10.12962/j26139960.v6i1.188 $\quad$ Naskah Masuk 30-11-2021; $\quad$ Naskah Diulas 23-12-2022; $\quad$ Naskah Diterima 31-01-2022

\title{
Penggunaan Adsorben dalam Pengolahan Limbah Pewarna dari Kerajinan Tenun Ikat di Desa Parengan, Kecamatan Maduran, Kabupaten Lamongan Sebagai Upaya Mengurangi Pencemaran Pewarna di Sungai Bengawan Solo
}

\author{
Adi Setyo Purnomo ${ }^{1, *}$ | Hendro Nurhadi ${ }^{2}$ | Refdinal Nawfa ${ }^{1}$ | Herdayanto Sulistyo Putro ${ }^{1}$ | Hamdan \\ Dwi Rizqi $^{1}$ | Muhammad Lukman Hakim² | Asranudin ${ }^{1}$ | Taufiq Rinda Alkas ${ }^{1}$ | Alya Awinatul \\ Rohmah $^{1}$ | Eka Pratiwi Yuniarti ${ }^{1}$ | Badzlin Nabilah ${ }^{1}$
}

${ }^{1}$ Departemen Kimia, Institut Teknologi Sepuluh Nopember, Surabaya, Indonesia

${ }^{2}$ Departemen Teknik Mesin Industri, Institut Teknologi Sepuluh Nopember, Surabaya, Indonesia

\section{Korespondensi}

*Adi Setyo Purnomo, Departemen Kimia, Institut Teknologi Sepuluh Nopember, Surabaya, Indonesia. Alamat e-mail: adi_setyo@chem.its.ac.id

Alamat
Laboratorium Kimia Mikroorganisme,
Departemen Kimia, Institut Teknologi
Sepuluh Nopember, Surabaya, Indonesia

\section{Alamat}

Sepuluh Nopember, Surabaya, Indonesia

\begin{abstract}
Abstrak
Industri tekstil merupakan salah satu industri yang berkembang pesat di Indonesia saat ini. Selain, menghasilkan produk tekstil, industri juga menghasilkan limbah warna. Desa Parengan yang terletak di Kabupaten Lamongan merupakan Desa yang telah dikenal sejak lama sebagai Desa industri penghasil kain tenun ikat. Pembuangan limbah pewarna di Desa tersebut masih dilakukan secara langsung ke badan Sungai Bengawan Solo. Hal tersebut sangat berdampak negatif terhadap biota Sungai, sehingga sangat diperlukan solusi untuk penanganan pengolahan limbah. Tim pengabdian Institut Teknologi Sepuluh Nopember telah membuat teknologi dekolorator berbasis kolom matriks yang mengandung adsorben super adsorpsi, yang merupakan hasil riset laboratorium kimia. Reaktor terhubung dengan kolom matriks yang berisi adsorben arang aktif-silika-zeolit. Sistem ini dapat menghilangkan limbah pewarna menjadi larutan yang aman dibuang di lingkungan. Tim abdimas ITS telah menyerahkan 1 unit reaktor kepada UMKM tenun ikat di Desa Parengan dimana diharapkan akan memberikan dampak signifikan terhadap pengurangan limbah pewarna di Sungai Bengawan Solo. Selain itu, kegiatan ini diharapkan dapat mengubah pola pikir warga desa untuk tetap selalu menjaga ekosistem lingkungan dan menggalakkan terciptanya Desa cerdas lingkungan.
\end{abstract}

Kata Kunci:

Dekolorisasi, Adsorpsi, Limbah warna, Tenun Ikat, Bengawan Solo. 


\section{1 | PENDAHULUAN}

Desa Parengan merupakan sebuah desa yang telah dikenal sebagai sentra industri kerajinan tenun ikat yang terletak di Kecamatan Maduran, Kabupaten Lamongan, Jawa Timur. Wilayah Lamongan yang tergabung dalam GERBANGKERTASUSILA (Gresik, Bangkalan, Mojokerto, Surabaya, Sidoarjo, Lamongan) tepatnya terletak di perlintasan pantai utara (Pantura), membuat perekonomian di Kabupaten Lamongan terus tumbuh, termasuk pertumbuhan Usaha Mikro Kecil dan Menengah (UMKM) tenun ikat yang berhasil menembus pasar dunia. Saat ini terdapat sekitar 50 Unit industri kain tenun ikat yang ada di desa ini sanggup menyerap tenaga kerja hingga 1000-1500 orang. Unit industri kain tenun ikat ini umumnya masih memakai alat tenun tradisional dan memakai pewarna sintetik dari berbagai golongan sebagai pewarna benang.

Industri tenun ikat di Desa Parengan telah ada pada masa kependudukan Belanda pada tahun 1924, sehingga pengetahuan tentang metode pewarnaan/ hubungan antara jenis pewarna dengan jenis benang telah dikuasai oleh seluruh pengrajin tenun ikat. Pewarna yang sering digunakan adalah pewarna reaktif seperti remasol dan pewarna azo lainnya yang diperoleh dari supplier wilayah Kia-Kia Kota Surabaya. Dalam proses pewarnaan seluruhnya dikerjakan secara manual ${ }^{11}$.

Secara umum, produk tenun di wilayah Desa Parengan dihasilkan oleh skala industri rumah tangga (home industry), yang mengakibatkan manajemen pengelolaan limbah masih terbilang sangat buruk. Desa Parengan ini tersmasuk salah satu Desa yang dilewati oleh Sungai terpanjang sepulau Jawa yaitu Sungai Bengawan Solo ${ }^{[2]}$. Sungai tersebut dimanfaatkan oleh warga sekitar untuk mencari ikan dan keperluan mandi. Selain itu, Sungai tersebut digunakan sebagai tempat buangan akhir limbah industri tenun, bahkan gudang pengolahan dan pewarnaan benang sengaja didirikan di bantaran sungai dengan tujuan mempermudah pembuangan limbah warna sisa pencelupan kain (Dyeing). Perilaku ini dapat memperparah pencemaran air Sungai Bengawasan Solo.

Berdasarkan kasus penanganan limbah yang buruk, maka tim pengabdian Institut Teknologi Sepuluh Nopember (ITS) mempunyai ide yaitu diseminasi paket teknologi berupa dekolorator berbasis kolom matriks adsorben super adsorpsi, yang merupakan hasil riset laboratorium Kimia Mikroorganisme. Reaktor ini terhubung dengan dekolorator adsorben (Silika-Karbon aktif-zeolit) dimana diharapkan akan dapat memberikan dampak signifikan terhadap isu dan jejaring permasalahan pengelolaan lingkungan di sekitar mitra terutama di sungai Bengawan Solo sebagai upaya menciptakan desa cerdas lingkungan.

\section{2 | METODE PENELITIAN}

\section{1 | Pihak-Pihak yang Terlibat}

Diseminasi teknologi dekolorisasi pada pengrajin tenun ikat Desa Parengan, Kecamatan Maduran, Lamongan merupakan hasil dari penelusuran tim pengabdi. Tim telah melakukan koordinasi dengan beberapa pihak, terutama kepada Mitra tempat pelaksanaan kegiatan pengabdian.

\section{2 | Metode dan Tahapan Penerapan Diseminasi}

Kegiatan diseminasi dekolorasi limbah pewarna akan dilakukan melalui beberapa pendekatan, antara lain:

1. Model Participatory Rural Appraisal (PRA), yang menekankan keterlibatan masyarakat dalam perencanaan, pelaksanaan dan evaluasi program kegiatan;

2. Model Participatory Technology Development, yang memanfaatkan teknologi tepat guna yang berbasis pada ilmu pengetahuan dan kearifan budaya lokal;

3. Model Community Development yaitu pendekatan yang melibatkan masyarakat secara langsung sebagai subjek dan objek pelaksanaan kegiatan diseminasi kepada masyarakat;

4. Persuasif yaitu pendekatan yang bersifat himbauan dan dukungan tanpa unsur paksaan bagi masyarakat untuk berperan aktif dalam kegiatan ini.

5. Edukatif yaitu pendekatan sosialisasi, pelatihan dan pendampingan sebagai sarana transfer ilmu pengetahuan dan pendidikan untuk pemberdayaan masyarakat. 


\section{3 | Persiapan Rangkaian Kegiatan Pengabdian}

Pada tahap persiapan ini dilakukan sosialisasi dan inventarisasi kelompok pengrajin tenun ikat sehingga desain kegiatan yang akan dilakukan dapat memberikan solusi bagi permasalahan mitra.

\section{4 | Pelaksanaan Kegiatan}

Pelaksanaan kegiatan diseminasi teknologi dekolorator kepada mitra dilakukan beberapa tahapan pelaksanaan yaitu menentukan titik pendirian reaktor dekolorisasi limbah pencucian benang.

\section{5 | Evaluasi dan Monitoring Kegiatan}

Evaluasi dan monitoring kegiatan dilakukan secara periodik dengan melibatkan anggota pelaksana dan tokoh masyarakat Desa Parengan. Evalusi yang urgent adalah sejauh apa mitra konsisten menggunakan reaktor sehingga limbah pewarna sintetik tersebut tidak sampai ke sungai Bengawan Solo.

\section{6 | Prosedur kerja}

Pencapaian target diseminasi akan mengikuti prosedur umum yaitu:

1. Sosialisasi program secara bersama-sama dengan stakeholder Pengadaan bahan atau material

2. Pendampingan penggunaan

3. Forum Group Discussion (FGD)

4. Evaluasi

5. Pelaporan program

6. Serah terimah perangkat reaktor dekolorisasi

\section{7 | Evaluasi Pelaksanaan dan Keberlanjutan Program}

Pelaksanaan sebuah program pemberdayaan masyarakat sering menemui jalan buntu, disebabkan masyarakat kurang bergairah dalam menjalankan alih teknologi. Pasang surut semangat tersebut dapat disebabkan kesadaran dan tingkat pendidikan, sehingga diperlukan penguatan melalui koordinasi dengan dinas terkait agar produk diseminasi yang dihasilkan dapat dioperasi sepanjang waktu. Untuk mendapatkan justifikasi dari mitra diseminasi sehingga perlu dilakukan evaluasi bulanan dengan menurunkan tim melakukan pemantauan dan wawancara langsung untuk menentukan solusi atas permasalahan yang dihadapi mitra.

Transfer teknologi kepada mitra sering berakhir dengan berakhirnya kontrak pengabdian, disebabkan Tim Diseminasi tidak memiliki tanggungjawab kepada masyarakat. Oleh karena itu, untuk mendukung keberlanjutan program diperlukan beberapa strategi yaitu membuat MoU antara DRPM ITS dengan pemerintah Desa Parengan. Melalui MoU tersebut sehingga terjalin berbagai kerjasama lebih lanjut terkait penanganan limbah warna pengrajin tenun ikat di Desa Parengan

\section{3 | HASIL KEGIATAN}

Tim dari Laboratorium Kimia Mikroorganisme ITS, terlebih dahulu melakukan riset studi ke Desa Parengan, sebagai Desa yang akan dituju serta ke mitra Industri seperti yang ditunjukkan pada Gambar 1. Dari hasil survei yang dilakukan, desa terssebut tepat dilintasi oleh Sungai Bengawan Solo (Sungai terpanjang di Pulau Jawa). Selain itu, kegiatan industri tenun ikat pada Desa Parengan memang terbilang sangatlah berkembang signifikan.

Dari hasil survei yang diperoleh proses pembuatan kerajinan tenun ikat ini sangat kompleks. Bermula dari benang yang dipintal kemudian diberi motif corak menggunakan tinta warna. Semua proses kegiatan dari awal sampai akhir dilakukan menggunakan tangan (handmade). Tehnik pembuatan kerajinan ini menggunakan tehnik celup ikat, dimana setelah diberi motif benang-benang tersebut diikat dengan sangat kencang, kemudian dicelup untuk diwarnai (Gambar 2). Pada proses pewarnaan inilah warna 
yang digunakan sangatlah bermacam-macam. Zat warna yang digunakan merupakan zat warna sistetis yang dibeli oleh para pengusaha dari Kota Surabaya. Zat warna tersebut memiliki nama istilah dagang. Pewarnaan tidak dilakukan cuma sekali, tetapi setelah proses pewarnaan, terdapat beberapa ikatan yang akan dilepas kemudian diwarnai kembali, agar memberikan warna yang berbeda terhadap satu produk tenun ikat. Selain itu, terdapat benang yang digunakan sebagai dasaran dalam proses penenunan nantinya. Benang ini pun, juga dipintal dan diwarnai. Setelah semua proses dilakukan tahap akhirnya adalah dilakukan proses tenun yang masih dilakukan secara manual (Gambar 3).

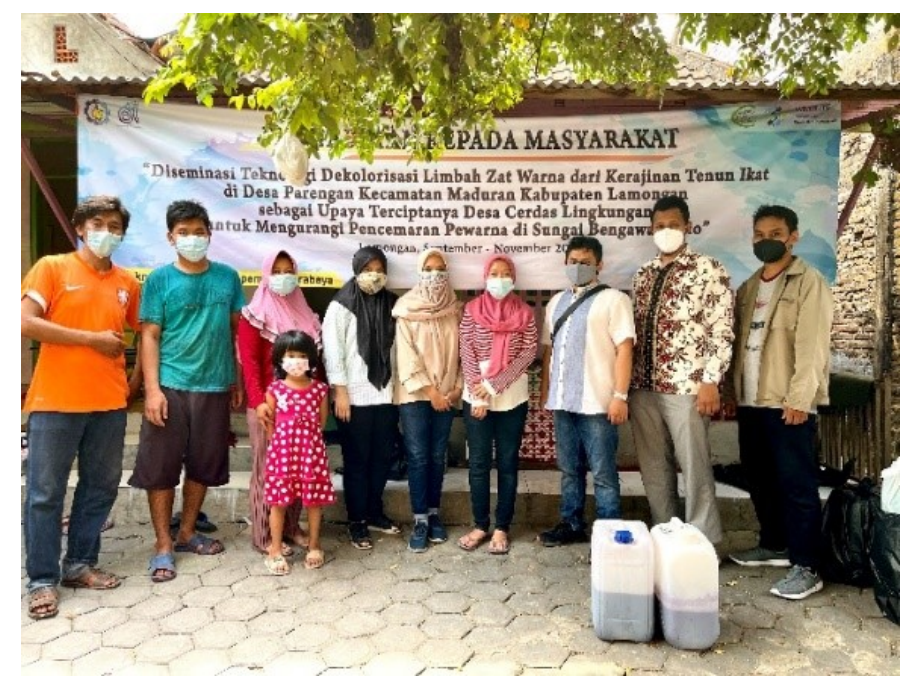

Gambar 1 Survei tempat lokasi mitra.

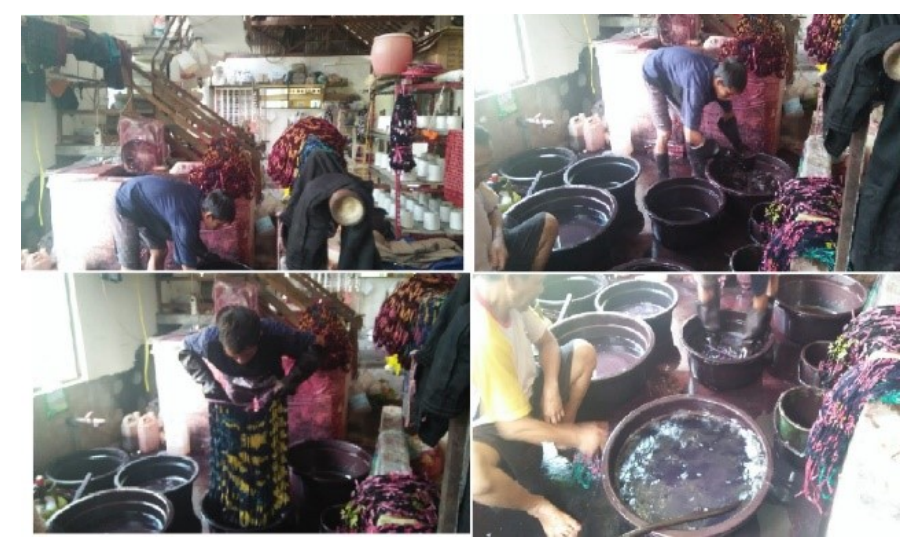

Gambar 2 Proses pewarnaan.

Produk pemasaran hasil tenun ikat ternyata tidak terlalu diprioritaskan untuk skala dalam negeri melainkan lebih ke skala luar negeri, yaitu diekspor ke Timur Tengah seperti Abu Dhabi, Yaman, Arab Saudi, dan daerah sekitarnya. Hal tersebut karena produk tenun ikat ini biasanya digunakan sebagai sarung yaitu salah satu pakaian untuk sholat. Sarung tenun ikat Parengan ini memiliki keunikan jika digunakan. Sarung akan terasa hangat jika dipakai saat suasana dingin dan sarung akan terasa sejuk (adem) jika dipakai pada suasana panas. Sarung ini kurang dapat bersaing di dalam negeri karena harganya yang lebih tinggi dibandingkan dengan sarung buatan mesin yang cukup terjangkau, harga sarung tenun ikat di pasaran adalah sekitar Rp 175.000 


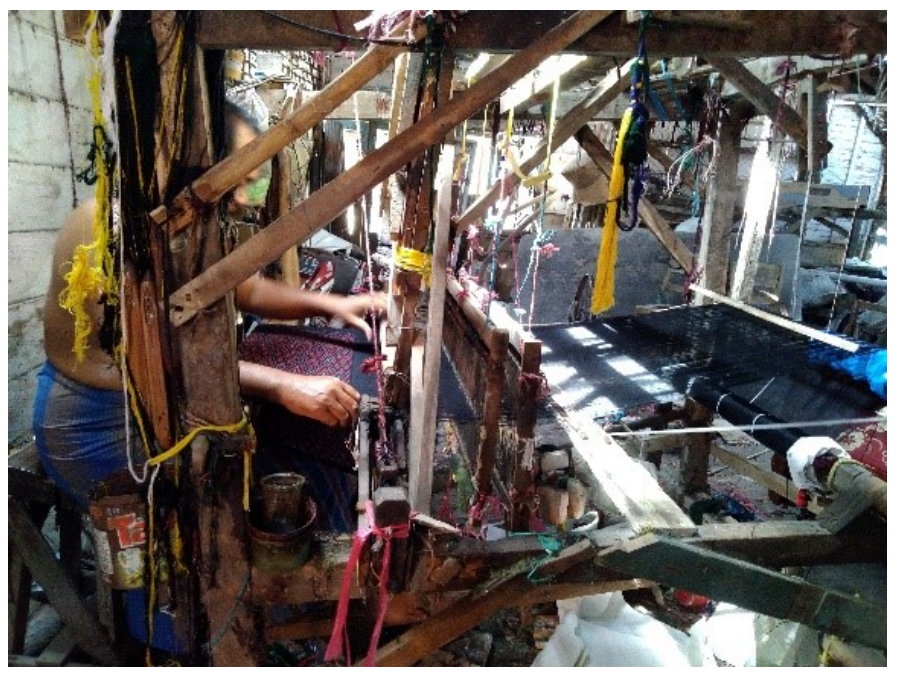

Gambar 3 Proses tenun.

hingga Rp 800.000 tergantung motif, warna, dan jenis bahan yang digunakan. Sedangkan sarung buatan mesin dipasaran memiliki harga mulai dari Rp 60.000 dan motifnya yang beragam. Akan tetapi, sarung tenun ikat Parengan ini masih tetap eksis kehadirannya, karena keunikan dan nilai esensi yang ada.

Dibalik citra produknya yang sangat mendunia, tentu saja usaha industri tekstil ini tak luput dengan limbah yang dihasilkan. Salah satunya yaitu limbah pewarna. Berhubung Desa Parengan ini terletak diseberang sungai Bengawan Solo, naasnya banyak home industry yang memanfaatkan sungai tersebut sebagai tempat pembuangan akhir limbah seperti yang ditunjukkan pada Gambar 4. Meskipun volume air sungai yang sangat besar, dimana jika limbah pewarna terbuang ke badan Sungai tidak terlalu mempengaruhi warna sungai, karena akan larut bersama dengan air sungai. Akan tetapi, limbah pewarna sintetis teksitil tersebut juga lambat laun akan mempengaruhi pencemaran ekosistem sungai.

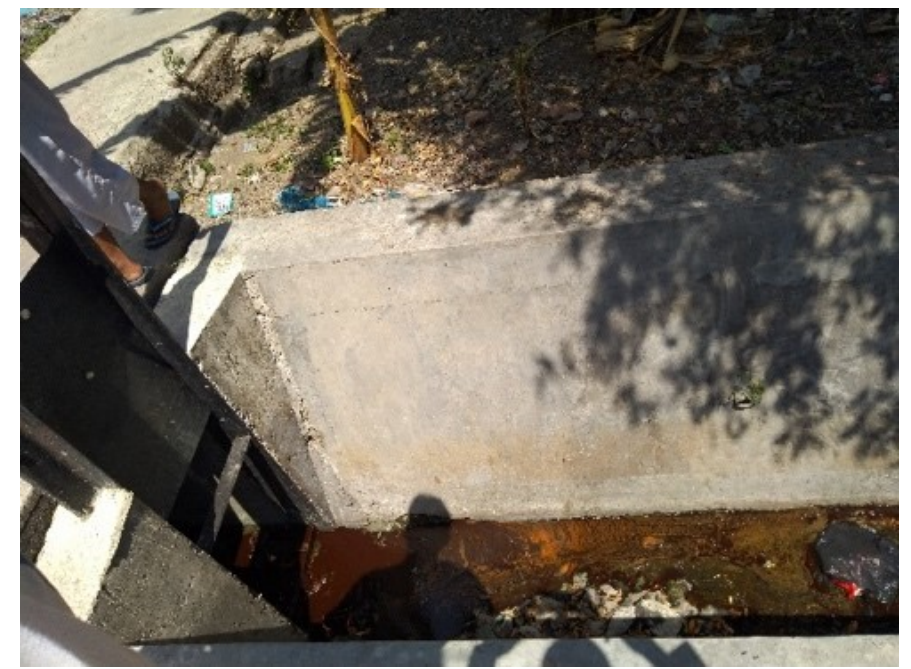

Gambar 4 Pembuangan limbah warna ke badan sungai Bengawan Solo.

Tim survei melihat bahwa pebuangan limbah langsung dialirkan ke selokan buangan rumah tangga dan selanjutnya berakhir ke Sungai Bengawan Solo. Bahkan terdapat beberapa tempat pencelupan kain tenun yang memang didirikan di dekat bantaran Sungai agar memudahkan proses pembuangan ke Sungai. Saat melakukan survei tersebut, memang para pengusaha menyadari 
akan efek dari limbah wana, jika terus menerus dibuang ke lingkungan. Akan tetapi, mereka berkata bahwa jika di treatment dengan waktu yang lama akan mengurangi efisiensi waktu, karena limbah pewarna yang dihasilkan terbilang cukup banyak.

Berdasarkan hasil survei tersebut, tim dari Laboratorium Kimia Mikroorganisme, membuat suatu desain reaktor dekolorisasi dengan memanfaatkan material superadsorbendi dalam reaktor tersebut. Desain reaktor ditunjukkan seperti pada Gambar 5, dimana tandon kuning berfungsi untuk menampung air limbah dan diisi adsorben yaitu batuan zeolit yang memiliki fungsi adsorben dan katalis ${ }^{3]}$. Selain itu, juga ditambahkanlah klorin cair agar air limbah berubah menjadi jernih dan dapat membunuh kuman yang ada di dalamnya ${ }^{[4}$. Setelah itu proses dilanjutkan ke tabung-tabung pipa yang berisi granula-granula karbon aktif, silika, dan manganese. Karbon aktif dan silica memiliki luas permukaan pori yang besar, sehingga memiliki kapasitas adsorpsi yang tinggi [5] 6 . Sedangkan, manganese memiliki fungsi menghasilkan Mn2+ yang bereaksi dengan zat-zat limbah dalam air dan membentuk endapan yang akan terperangkap dalam media filter ${ }^{[7]}$.

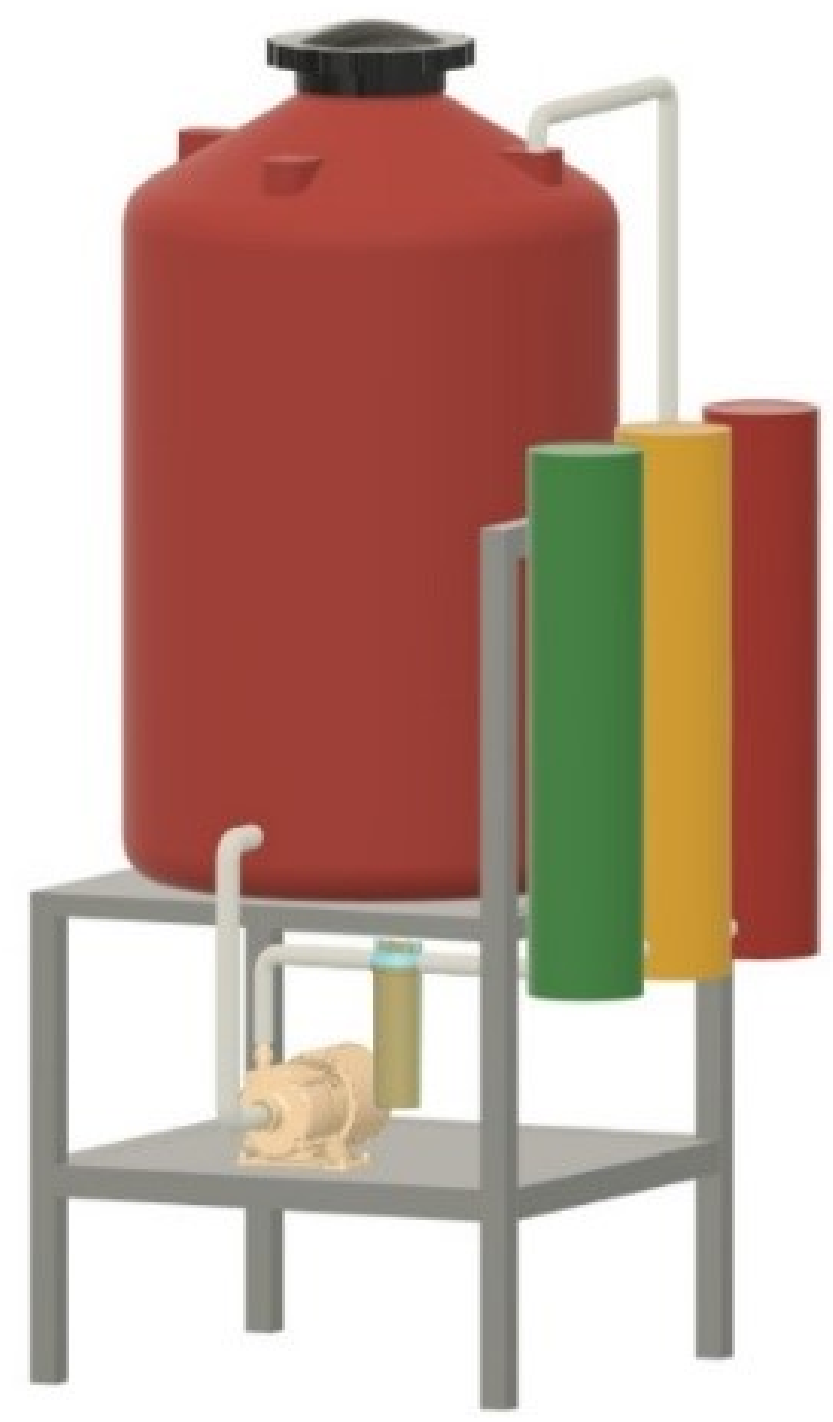

Gambar 5 Desain reaktor dekolorisasi.

Proses pembuatan reaktor dilakukan di Departemen Tehnik Mesin Industri, dimana selanjutnya trial adsorben yang digunakan untuk penjernihan dilakukan di Laboratorium kimia mikroorganisme. Perlu dilakukan beberapa trial untuk memperoleh hasil yang maksimal, sehingga didapatkan luaran air limbah yang telah berubah menjadi jernih 


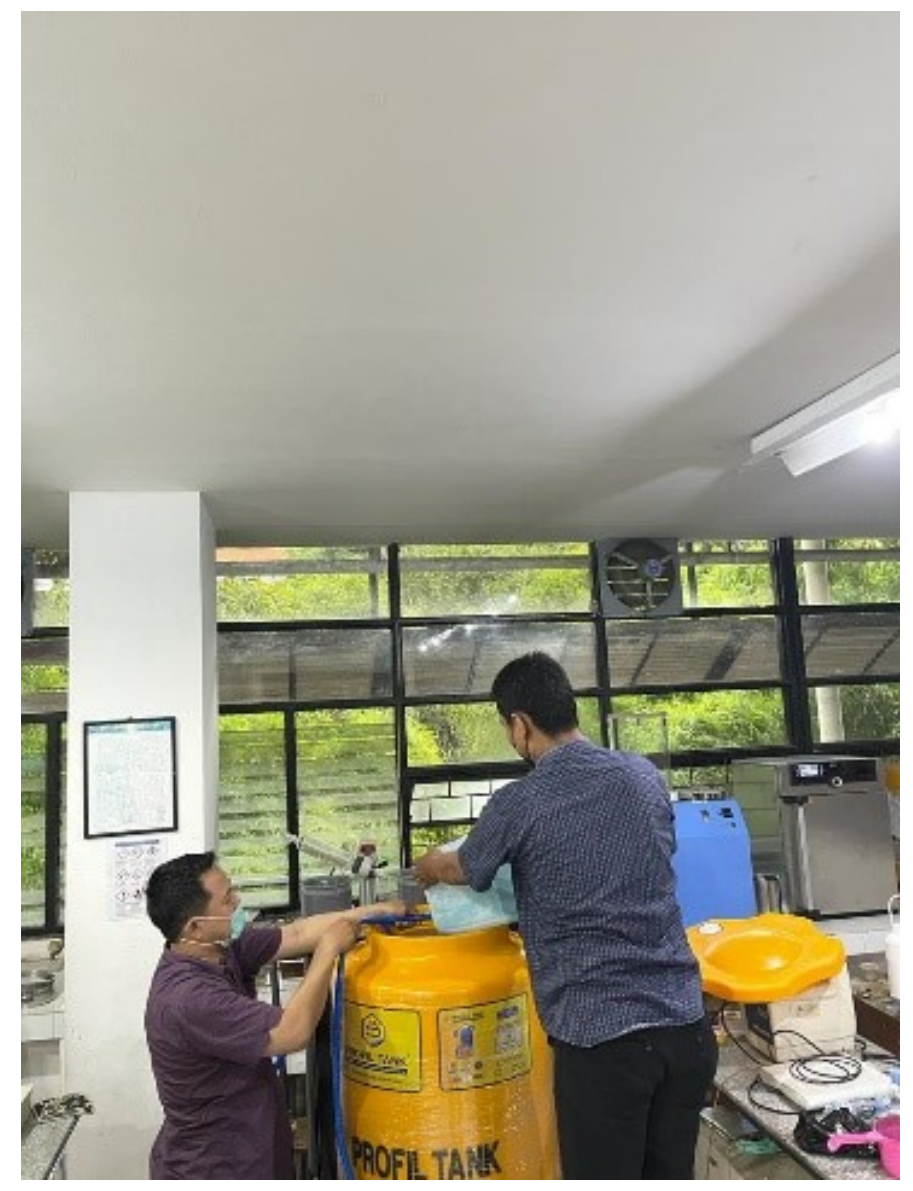

Gambar 6 Proses trial reaktor dekolorisasi.

Setelah proses pembuatan reaktor dan trial untuk dekolorisasi zat pewarna, tim melakukan instalasi di tempat yaitu di Desa Parengan Kecamatan Maduran Kabupaten Lamongan (Gambar 7). Setelah itu dilakukanlah sosialisasi tentang penggunaan teknologi alat dan bahaya limbah pewarna tekstil, terutama pada mitra dan rekan-rekan pengusaha home industry tenun ikat Parengan (Gambar 8). Diseminasi teknologi reaktor dekolorisasi tersebut dapat menjadi suatu alternatif terbarukan yang berbasis teknologi dan keilmuan kimia yang nantinaya diharapkan dapat mengatasi solusi terhadap pembuangan limbah pewarna kerajinan tenun ikat di Desa Parengan Kecamatan Maduran Kabupaten Lamongan. Nantinya dekolorator ini juga diharapkan dapat mengurangi pencemaran lingkungan pada Sungai Bengawan Solo.

\section{4 | KESIMPULAN}

Diseminasi reaktor dekolorisasi limbah pewarna tekstil untuk kegiatan industri kain tenun ikat di Desa Parengan Kecamatan Maduran Kabupaten Lamongan dapat menjadi solusi agar warga serta pengusaha tekstil tersebut lebih sadar terhadap sikap kepedulian lingkungan dan sekitar. Selain itu, pemanfaatan teknologi dan keilmuan harus tetap selalu dikembangkan agar dapat teraplikasikan terhadap kehidupan dan terlebih lagi jika dapat bermanfaat untuk orang banyak. Proyek diseminasi yang dilakukan Tim Peneliti menggunakan prinsip dari material superadsorpsi seperti karbon aktif, zeolit, silika, dan manganese, yang juga ditambahkan dengan klorin, agar limbah tekstil dapat di-treatment dengan baik dan selanjutnya dapat dibuang ke lingkungan secara aman. 


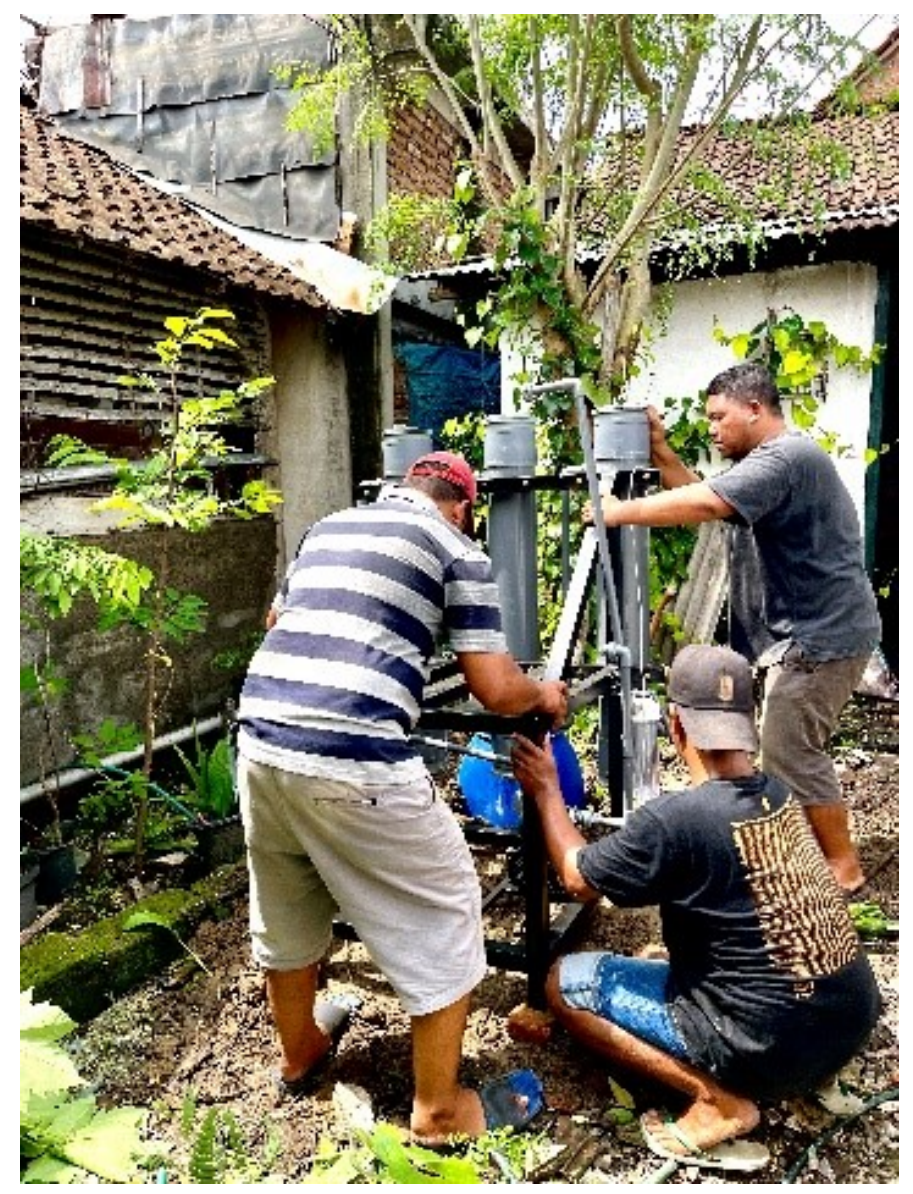

Gambar 7 Instalasi reaktor di tempat mitra.

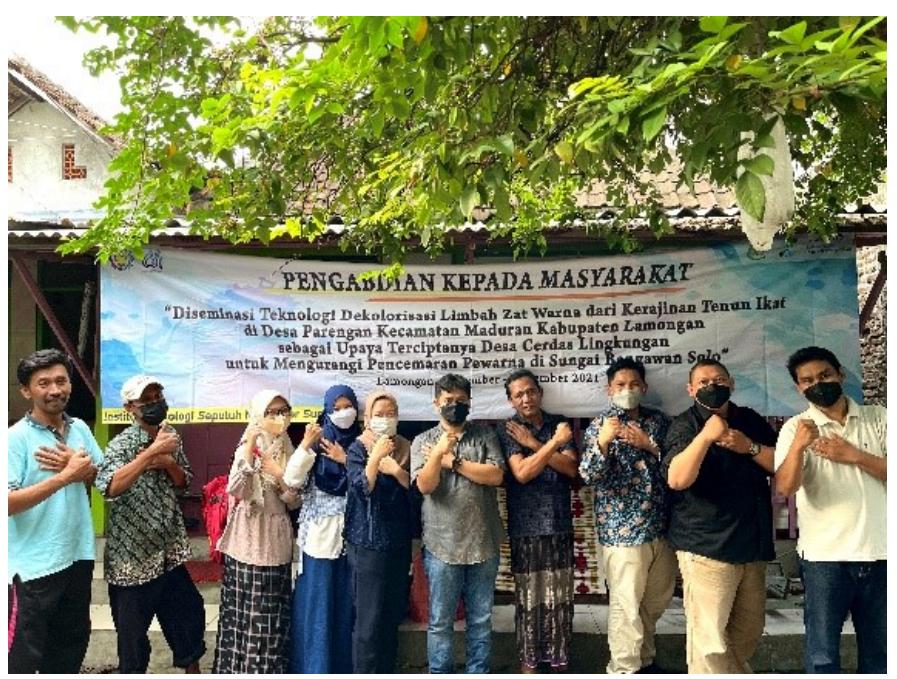

Gambar 8 Sosialisasi tentang diseminasi reaktor dekolorisasi.

\section{5 | UCAPAN TERIMA KASIH}

Terima kasih kepada DRPM ITS yang telah memberikan pendanaan melalui Pengabdian Masyarakat Reguler Dana Lokal ITS Tahun 2021 sesuai surat perjanjian pelaksanaan pengabdian masyarakat no 1446/PKS/ITS/2021. Selain itu, tim ITS juga berterima kasih kepada rekan mitra Mohammad Wisnu Sugiyanto sebagai owner dari salah satu home industry kain tenun ikat yang ada di Desa Parengan Kecamatan Maduran Kabupaten Lamongan. 


\section{Referensi}

1. Nurdiyansah A. Perjalanan Panjang Tenun Ikat Lamongan. https://wwwmytripcoid/article/perjalanan-panjang-tenun-ikatlamongan, Retrieved Nov 30, 2021 2019;

2. M RNL. Mengenal Sarung Tenun Ikat Parengan Lamongan, Terancam karena Minim Generasi Muda. https://wwwmerdekacom/jatim/mengenal-sarung-tenun-ikat-parengan-lamongan-terancam-karena-minim-generasimudahtml, Retrieved Nov 30, 2021 2019;

3. Li CJ, Zhang YJ, Chen H, He PY, Zhang Y, Meng Q. Synthesis of fly ash cenospheres-based hollow ABW zeolite for dye removal via the coupling of adsorption and photocatalysis. Advanced Powder Technology 2021;32(10):3436-3446.

4. Kandinska M, Cheshmedzhieva D, Kostadinov A, Rusinov K, Rangelov M, Todorova N, et al. Tricationic asymmetric monomeric monomethine cyanine dyes with chlorine and trifluoromethyl functionality-Fluorogenic nucleic acids probes. Journal of Molecular Liquids 2021;342:117501.

5. Quirós J, Gonzalo S, Jalvo B, Boltes K, Perdigón-Melón JA, Rosal R. Electrospun cellulose acetate composites containing supported metal nanoparticles for antifungal membranes. Science of the Total Environment 2016;563:912-920.

6. Xue H, Wang X, Xu Q, Dhaouadi F, Sellaoui L, Seliem MK, et al. Adsorption of methylene blue from aqueous solution on activated carbons and composite prepared from an agricultural waste biomass: A comparative study by experimental and advanced modeling analysis. Chemical Engineering Journal 2022;430:132801.

7. Outram JG, Couperthwaite SJ, Millar GJ. Investigation of manganese greensand activation by various oxidants. Journal of environmental chemical engineering 2018;6(4):4130-4143.

Cara mengutip artikel ini: Purnomo, A.S., Nurhadi, H., Nawfa, R., Putro, H.S., Rizqi, H.D., Hakim, M.L., Asranudin, Alkas, T.R., Rohmah, A.A., Yuniarti, E.P., Nabilah, B., (2022), Penggunaan Adsorben dalam Pengolahan Limbah Pewarna dari Kerajinan Tenun Ikat di Desa Parengan, Kecamatan Maduran, Kabupaten Lamongan Sebagai Upaya Mengurangi Pencemaran Pewarna di Sungai Bengawan Solo, Jurnal Sewagati, 6(1):107-115. 